\title{
ANÁLISE DOS TEMAS APRESENTADAS NA 2.० SEMANA DA ENFERMAGEM, ABERTA À COMUNIDADE
}

\author{
* Elisete Silva \\ * Elza Maria Lourenço Ubeda \\ * João Carlos Pedrazzani
}

\begin{tabular}{|l|l|}
\cline { 2 - 2 } & $\mathrm{RBEn} / 07$ \\
\hline
\end{tabular}

SILVA, E. e Colaboradores - Análise dos temas apresentados na 2. semana da enfermagem, aberta à comunidade. Rev. Bras. Enf.; DF, 32 : 213-216, 1979.

Para a organização da Semana da Enfermagem, foi constituída uma comissão cujos membros eram do corpo docente e discente do Curso de Enfermagem da Universidade Federal de São Carlos.

Após reuniões dessa comissão, pla.nejou-se que a Semana da Enfermagem seria programada utilizando-se os recursos da comunidade e levando em conta que para uma maior participação de membros desta comunidade, não seria cobrada taxa de inscrição. Para a promoção pudemos contar com a colaboração do comércio e indústrias locais, e também com a ativa participação dos órgãos de imprensa falada e escrita.

A comissão decidiu pela abordagem do tema "Seminário de Saúde Pública", pela atual conjuntura do sistema polí- tico-social-econômico e educacional que interfere diretamente no nível de saúde da população.

Ao abordar aspectos de saúde de una população, tendo como base o atual sistema, procura-se através de uma ação comunitária, fazer com que a população seja realmente atuante na identificação e resolução de seus problemas.

Por ser o Curso de Enfermagem da Universidade Federal de São Carlos n primeiro na área de saúde nesta cidade, que conta atualmente com aproximadamente 120.000 habitantes, a Comissão julgou a necessidade de discutir junto à comunidade o Sistema Nacional de Saúde, enfocando os seus aspectos preventivos, e mostrando que um elemento da prória comunidade, orientado por profissionais da área de saúde, pode

* Auxiliares de Ensino do Curso de Enfermagem do Departamenţo de Ciências da Saúde - Universidade Federal de São Carlos.

- Este trabalho refere-se à Semana de Enfermagem do ano 1978. 
SILVA, E. e Colaboradores - Análise dos temas apresentados na 2. semana da enfermagem, aberta à comunidade. Rev. Bras. Enf.; DF, 32 : 213-216, 1979.

participar de forma ativa junto aos seus semelhantes.

O Seminário de Saúde Pública foi organizado de forma sistêmica com o objetivo de atingir a comunidade e despertar interesse para que este venha participar de programas de saúde a serem desenvolvidos juntamente com os profissionais que nela atuam.

Em 1975, a 28. ${ }^{\text {a }}$ Assembléia Mundial de Saúde declarou que a atenção primária de saúde é o ponto inicial de onde o individuo na Comunidade estabelece contato com o Sistema Nacional de Saúde, do qual deve ser parte integrante, deve guardar estreita relação com os tipos de vida e as necessidades da comunidade a que serve, e deve estar plenamente integrado com os demais setores envolvidos e em desenolvimento da comunidade (1).

$\mathrm{Na}$ palestra de abertura foi apresentado o Curso de Enfermagem da Un:versidade Federal de São Carlos e sua organização, que tem como filosofia de trabalho, desenvolver a maior carga curricular aplicada ao "homem sadio" no seu ecossistema.

As demais palestras foram centralizadas na problemática que envolve a identificação e resolução das necessidades básicas que interferem na saúde do ser humano no seu meio ambiente, procurando caracterizar as implicações encontradas na prevenção da doença e promoção da saúde.

Para prevenir doença e promover saúde do ser humano - indivíduo e família - temos que considerar a existência de diferentes sistemas interdependentes entre si como político, econômico e social que por sua vez são independentes do sistema de saúde.
Apesar da ausência de dados estatísticos seguros, enquanto atualizados, capazes de delinear com nitidez o quadro de saúde no país e a influência que nele exercem os fenômenos sociais e a ação planificada; o fato é que evidências desse tipo vêm fazendo consolidarse entre os planejadores governamentais, a convicção de que a saúde é um problema indissociável da renda.

Não há dúvida, e parece demonstrado, que a assistência à saúde e o desenvolvimento econômico são dois problemas que não podem ser equaciona. dos isoladamente.

Em trabalho realizado pelo Dr. Walter Leser, Secretário de Saúde do Estado de São Paulo (2), encontramos dados em que se compara objetivamente a variação sofrida pelos salários nos últimos dezessete anos com os índices de saneamento urbano e de mortalidade infantil no Estado.

Ostensivamente convincente o Gráfico 1 revela que a perda do valor do salário-mínimo e a redução dos índices de saneamento em relação ao crescimento da população conduzem, com uma coerência espantosa, à elevação da taxa de mortalidade infantil.

No Brasil, perdura ainda o velho hábito de imaginar as nossas necessidades sanitárias, pelo padrão dos países altamente desenvolvidos.

Sabe-se que os serviços de assistência médico-sanitário são, naturalmente mantidos na superestrutura da sociedade, e só conseguem ter as dimensōes que a infraestrutura pode suportar, portanto não é possível manter uma assistência à saúde em um país subdesenvolvido, de renda "per capita" baixa. iguais aos países desenvolvidos, que

(1) Hector R. Acuña - Discurso proferido na IX Conferência Internacional sobre Educação para Saúde - Ottava, Canadá, 29 de agosto a 03 de setembro de 1976.

(2) Revista Visāo, 18 de abril de 1977. 
SILVA, E. e Colaboradores - Análise dos temas apresentados na 2. ${ }^{\text {a }}$ semana da enfermagem, aberta ̀̀ comunidade. Rev. Bras. Enf.; DF, 32 : 213-216, 1979.

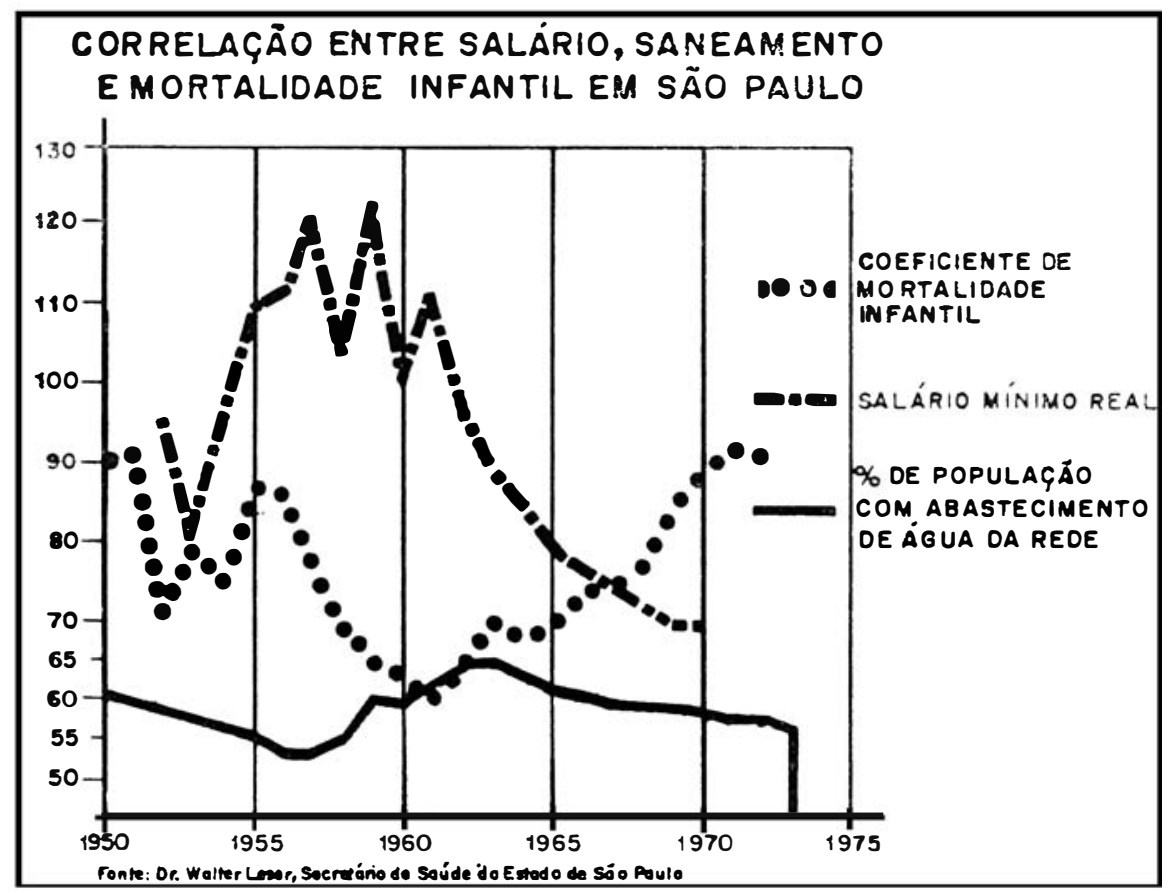

possuem uma renda "per capita" elevada.

Os indivíduos mais afetados pela doença e por sua vez mais carentes de recursos preventivos e curativos, geralmente residem nas periferias de zonas urbanas ou mesmo na zona rural, isto porque o desenvolvimento na atual política no regime capitalista tem favorecido migração da zona rural para a zona urbana e esta população pelo seu baixo poder aquisitivo, sua desinformação, e, principalmente, pela centralização das instituições de saúde nestes centros urbanos, vem sofrendo as consequiências da desorganização, refletindose esses fatos no agravamento do nível de saúde da população brasileira.

Além disso, ainda temos que contar com o viés encontrado nas instituições de saúde representado pelo pessoal militante que não desempenha suas funções de maneira satisfatória condizente com a qualidade dos serviços a serem prestados àqueles que conseguem chegar a receber alguma forma de assistência à saúde.

Quando se fala em Sistema Nacional de Saúde para um país como o nosso, temos que entender que existem inúmeras forças sociais em jogo, e é do jogo destas forças que vai resultar a definição do sistema; que para definir este sistema de saúde para o país, deve-se levar em consideração que já houve inúmeras tentativas de se formular uma política nacional de saúde, mas todas estas foram fracassadas.

O que nos chama a atenção para a necessidade de inverter o rumo do processo que pretende envolver uma medicina comercializada, são os aspectos relacionados aos próprios profissionais de saúde que devem assumir o seu papel social e a sua responsabilidade de pelo menos tentar diminuir as deturpaçōes apresentadas até aqui no Sistema de Saúde. Consideramos ainda que a 
SWVA, E. e Colaboradores - Análise dos temas apresentados na 2.^ semana da enfermagem, aberta à comunidade. Rev. Bras. Enf.; UF, 32 : 213-216, 1979.

participaçāo da comunidade é de real importância para a extensão da cobertura dos serviços de saúde e é através de suas próprias necessidades e de seus recursos disponiveis que o indivíduo vai adquirir um senso de responsabilidade voltado para o aprimoramento de sua situaçāo real e adquirir motivação para solucionar seus problemas comuns, relacionando-os às melhores condiçōes do seu ambiente e ao progresso social, econômico e educacional de outros grupos humanos.

Considerando os aspectos apresentados no texto, vimos que é difícil definir um sistema que concilie o inconciliável, pois a definição do que se vai fazer em termos de saúde tem que surgir de uma discussão profunda ao nível da chamada periferia do sistema, ao nível dos profissionais que estão trabalhando, que estão empregando todo o seu vigor e atividade para fazer com que a população tenha alguma atenção em termos de saúde.

\section{RECOMENDAÇAO}

Acreditamos que as reivindicaçōes fundamentais dos trabalhadores na área de saúde têm que ser discutidas democraticamente; as decisōes que estão sendo tomadas para que o sistema venha a ser gerado, devem refletir muito mais a realidade, com que a maioria dos profissionais da saúde estão convivendo, do que outras realidades tendentes à busca de excelências de trabalhos dos grupos profissionais de saúde, onde não tem acesso a própria população, que continua distante das decisōes e apresentando a evidência de estilos de vida inadequados ao bem-estar e nível de saúde.

\section{BIBLIOGRAFIA}

CAMARGO, Cāndido Procopio Ferreira de - São Paulo, 1975. Crescimento e Pobreza, 5. ${ }^{\text {a }}$ edição. Ediçōes Loyola, 1976, $160 \mathrm{p}$.

CHAVES, Mário M. - Saúde e Sistema, Fundação Getúlio Vargas. Rio de Janeiro, 1972. $207 \mathrm{p}$.

CUPERTINO, Fausto - Populaçāo e Saúde Pública no Brasil (Povo pobre é povo doente). Rio de Janeiro, Civilização Brasileira, 1976. 110 p.

DONNANGELO, Maria Cecília Ferro - Sau. de e Sociedade, Livraria Duas Cidades, 1976. 124 p.

MELLO. Carlos Gentile de - Saude e Assistència Médica no Brasil, Cebes-Hucitec, 1977. $269 \mathrm{p}$.
BRASIL, Ministério da Saúde - Sistema Nacional de Saúde, V Conferência Nacional de Saúde, 1975.

O.P.A.S. - O.M.S. - IV Reunião Especial le Ministros da Saúde das Américas. Washington, D.C. - 26-27 de setembro de 1977.

REVISTA DE ADMINISTRAÇÃO PÚBLICA - Rio de Janeiro, Fundação Getúlio Vargas, 1977, vol. 11.

REVISTA SAÚDE EM DEBATE - São Paulo, Centro Brasileiro de Estudos de Saúde, 1976, n. ${ }^{\circ} 1$.

PALESTRAS proferidas na 2. ${ }^{a}$ Semana da Enfermagem da Universiaade Federal de São Carlos. 